\title{
BMJ Open Increase in assisted suicide in Switzerland: did the socioeconomic predictors change? Results from the Swiss National Cohort
}

Nicole Steck, ${ }^{1}$ Christoph Junker, ${ }^{2}$ Marcel Zwahlen, ${ }^{1}$ For the Swiss National Cohort

To cite: Steck N, Junker C, Zwahlen M, et al. Increase in assisted suicide in Switzerland: did the socioeconomic predictors change? Results from the Swiss National Cohort. BMJ Open 2018;8:e020992. doi:10.1136/ bmjopen-2017-020992

- Prepublication history and additional material for this paper are available online. To view these files, please visit the journal online (http://dx.doi. org/10.1136/bmjopen-2017020992).

Received 5 December 2017 Revised 12 March 2018 Accepted 14 March 2018

\section{Check for updates}

${ }^{1}$ Institute of Social and Preventive Medicine (ISPM), University of Bern, Bern, Switzerland

${ }^{2}$ Federal Statistical Office, Neuchâtel, Switzerland

Correspondence to

Dr Nicole Steck;

nicole.steck@ispm.unibe.ch

\section{ABSTRACT}

Objective To determine whether the strong increase in assisted suicides in Switzerland since 2008 is linked to a shift in the socioeconomic factors associated with assisted suicide and its related diagnoses.

Methods In a population-based longitudinal study, we investigated assisted suicides in Switzerland over the period 2003-2014. Two groups of younger (25-64 years) and older (65-94 years) persons were analysed separately and compared. We calculated crude rates and used Cox proportional hazard and logistic regression models to examine associations of assisted dying with gender, marital status, education, religion, neighbourhood socioeconomic status and other variables, and investigated trends over time.

Results We identified 3941 assisted suicides among 6237997 Swiss residents, 80\% of which occurred in the older age group. Crude rates of assisted suicide more than tripled during the study period from 3.60 to 11.21 per 100000 person-years; the increase was more pronounced in the older age group. Cancer was the most common underlying diagnosis $(41.8 \%)$, but the percentage dying assisted was highest among patients with diseases of the nervous system $(5.25 \%$ in the younger and $1.23 \%$ in the older age group). The factors associated with assisted suicide did not change during the study period. Female gender, higher education, having no religious affiliation, no children and a Swiss passport, living in a neighbourhood with a higher socioeconomic index and living in the French-speaking part of Switzerland were associated with a higher rate. Conclusions The study results do not indicate any shift in socioeconomic factors associated with assisted suicide, but a more pronounced increase in incidence among the elderly.

\section{INTRODUCTION}

Switzerland is one of few countries worldwide that allows assisted suicide. ${ }^{1-3}$ According to article 115 of the Swiss Penal Code, assistance with suicide is only considered a crime and open to prosecution if selfish interests are involved. ${ }^{4}$ Though lawmakers did not have a medical perspective when article 115 was created in 1918, judgements of the Tribunal
Strengths and limitations of this study

The nationwide cohort study with virtually complete coverage and data at individual, household and building levels allows investigating time trends in the association of assisted dying with detailed socioeconomic characteristics in Switzerland, one of the few countries with long-term experience in assisted dying.

- In Switzerland, there is no obligation to report assisted suicides to a central registry, so the case records may not be complete. However, the Federal Statistical Office makes a great effort to identify assisted suicides, in cooperation with right-to-die organisations, institutes of forensic medicine and physicians.

- Most socioeconomic variables come from census 2000 and may not be completely up to date in 2014 for all individuals. However, particularly in the older age group characteristics such as education, religion and language region are quite stable.

- For information on the underlying disease, the study relies on the diagnoses given on the death certificate. Besides the issue of the reliability of these diagnoses, no information is available on the disease stage or severity.

Federal supported the activities of rightto-die organisations ${ }^{5}$ which, in general, are involved in the process of assisted suicide in Switzerland. ${ }^{6}$ These organisations assist their members in dying after a physician has confirmed both a person's ability to make decisions and that the person requesting assistance suffers from a terminal illness, an unendurable incapacitating disability or unbearable and uncontrollable pain. ${ }^{3}$ While the role of the physician in physician-assisted suicides is limited to prescribing a lethal drug, in euthanasia the physician injects the lethal drug when requested by the patient. Euthanasia is prohibited in Switzerland.

In an earlier study of the period 20032008, we reported higher rates of assisted 
suicide in Switzerland among women, persons who live alone or are divorced, and persons with higher education and higher socioeconomic status. ${ }^{7}$ Cancer was the most frequently diagnosed disease in assisted suicide, while the proportion of assisted deaths among patients with diseases of the nervous system was much higher. In the last 15 years, the numbers of assisted suicides reported by right-to-die organisations increased substantially in Switzerland. ${ }^{89}$ While the three main right-to-die organisations reported fewer than 200 assisted suicides of Swiss residents per year at the beginning of the century, in 2014 the number exceeded 760 (online supplementary table 1). ${ }^{10-12}$ Similar increases have been observed in other European countries and USA states that allow assisted suicide or euthanasia. ${ }^{13-20}$ This has intensified the debate about the ethics and prohibition or control of assisted death both in Europe and worldwide. One main concern about assisted dying is the so-called slippery slope, a shift from exceptional to routine practice that puts pressure on patients who are chronically ill and socioeconomically vulnerable. ${ }^{21-23}$

This study examined whether the increase in assisted suicides since 2008 is linked to a shift in the socioeconomic factors associated with assisted suicide. We wanted to identify groups with a disproportional increase in the rate of assisted dying and investigate possible shifts in diagnoses. Thus, we wanted to test the slippery slope hypothesis that there is an intensified trend towards dying with assistance among patients who are more vulnerable: those with less education, who live in lower socioeconomic status neighbourhoods, and also among persons who live alone and have no children.

\section{METHODS}

\section{The Swiss National Cohort}

The Swiss National Cohort (SNC) is a longitudinal study of the Swiss population described in detail elsewhere. ${ }^{24} 25$ The current version of the SNC is based on census data from 1990 to 2000 that were linked to mortality and emigration records until 2014, and to the newly introduced Registry-Based Census (RBC) 2011 using deterministic and probabilistic linkage procedures. Participation in the Swiss census is mandatory, resulting in a coverage of $99 \%$ in the census $2000 .{ }^{26}$ This analysis is based on the census 2000 and we included people who were between 25 and 95 years old during the study period 2003-2014. For exposing variables (education, religion, etc) information from the census 2000 was used because the RBC does not contain the same, detailed information. An exception is marital status, for which we had information on the last change in status before RBC 2011, respectively, before death, and used the relevant information. All individuals were followed from 1 January 2003 until death, emigration or the end of the study period on 31 December 2014.

\section{Patient and public involvement}

Neither patients nor public were involved in the development of the research question, in the analysis and in drawing conclusions from the results.

\section{Identification of assisted suicides}

During the study period, it was mainly three right-to-die associations that were active in assisting Swiss residents in dying: Exit in the German-speaking part, Exit in the French-speaking part of Switzerland and Dignitas. The organisations have been described in detail elsewhere. ${ }^{127}$ The Federal Statistical Office (FSO) identifies assisted deaths based on information given by the physician or the Institute of Forensic Medicine on the death certificate, assigning code X61.8 for assisted deaths since the International Classification of Diseases (ICD) has no code for assisted death. ${ }^{9}$ For the years 2003-2012, the right-to-die associations additionally provided anonymous data to the FSO on all deaths of Swiss residents they assisted.

\section{Determination of underlying diseases}

We used the ICD-10 codes on death certificates to determine the diseases underlying assisted suicides. Because until 2008, suicide by poisoning was indicated as primary cause of death for assisted suicides in the Swiss mortality statistics, we used the first, concomitant disease as the underlying cause for assisted suicides from 2003 to 2008. In 2009, the FSO changed the practice of coding according to the ICD definition of the primary cause of death as 'the disease or injury which initiated the train of morbid events leading directly to death ${ }^{92}$ : the underlying disease is labelled as primary cause and assisted suicide as a concomitant circumstance. For 2009-2014, we thus used a death certificate's primary cause of death to determine the disease underlying assisted suicides. For all other deaths the primary cause of death was used throughout the study period.

We created broad categories of all cancers, mental and behavioural disorders, diseases of the nervous system, diseases of the circulatory system, diseases of the respiratory system, diseases of the musculoskeletal system, and other diseases, and more detailed categories for the most common diagnoses (online supplementary table 2). We excluded all deaths with external causes such as accidents, unassisted suicide and assault (V, W, X and Y, except X61.8).

\section{Statistical analysis}

Within the SNC, we performed a survival analysis with age as time scale, and observation interval starting at 1 January 2003 and ending on the earliest of the date of death or emigration, or 31 December 2014. We calculated crude rates of assisted suicide and estimated HRs using Cox proportional hazard regression. The multivariable model included gender, religion (Protestant, Catholic, no affiliation, other/unknown), education (compulsory, secondary, tertiary), marital status (single, married, widowed, divorced), type of household (single person, 
two or more persons, institution) having children, urbanicity (urban, periurban, rural), the Swiss neighbourhood index of socioeconomic position (in quintiles), ${ }^{29}$ language region (German, French, Italian) and nationality (Swiss, foreign). The result of Cox proportional hazard regression might identify risk factors for assisted suicide and for being terminally ill or being in chronic and uncontrollable pain and suffering. Therefore, we also performed a logistic regression to identify determinants of assisted suicide among all deaths. We included the same variables and characteristics as in the Cox analysis, and also age at death (in 10-year bands) and underlying diagnosis (according to broad categories, see above). Earlier studies showed interactions between age group and other variables. ${ }^{7}$ The multivariable analyses were therefore stratified by interval (2003-2008 and 20092014 ), and by age group (25-64 and 65-94). The cut-off at 65 years reflects retirement age for men in Switzerland. In multivariable analyses, we tested for interaction between variables and period by including appropriately constructed interaction terms and performing likelihood ratio tests. For potentially fatal diseases, we also calculated the percentage of assisted deaths with a certain underlying cause among all deaths with the same condition.

Statistical analyses were done with Stata V.14 (StataCorp, College Station, TX, USA). Results are given as rates per 100000 person-years, HRs, ORs, and $\chi^{2}$ and $p$ values from Wald tests for overall model significance. Percentages of assisted suicides among all deaths across underlying causes are reported with $95 \%$ CIs.

\section{RESULTS}

\section{Study population}

We included 6237997 persons who participated in the 2000 census and were between 25 and 95 years old in the study period 2003-2014. Among this population, 5102268 were in the cohort 25-64 years, 2139152 were in the cohort 65-94 years and 1003423 were represented in both during the study period (table 1A,B).

We counted a total of 3941 assisted suicides between 2003 and 2014. This corresponds to $95.2 \%$ of the number of assisted suicides of Swiss residents officially reported by the three main right-to-die organisations in their annual reports (online supplementary table 1). The number of assisted suicides increased from 180 in $2003(0.32 \%$ of all deaths $)$ to 688 in $2014(1.30 \%$ of all deaths). While one-quarter of assisted suicides occurred in persons younger than 65 during the years 2003 and 2004, the proportion decreased to 15\% during 2013 and 2014. Crude rates more than tripled from 3.60 per 100000 person-years during the 2-year period 2003-2004 to 11.21 during 2013-2014. The rates increased in both age groups, but it was more pronounced in the age group 65-94 years, in which it rose from 12.23 to 35.35, than among those 25 to 64 years old, for whom it rose from 1.17 to 2.34 (table $1 \mathrm{~A}, \mathrm{~B}$, figure 1 ). Rates increased exponentially with age from 0.14 (95\% CI 0.063 to 0.314$)$ per
100000 person-years at age 25 to 56.25 (95\% CI 49.76 to $63.58)$ per 100000 at age 90 . Overall, crude rates were higher in women $(6.81,95 \%$ CI 6.54 to 7.10$)$ than in men $(5.37,95 \%$ CI 5.12 to 5.63$)$, but stratified by age women have a higher rate until the age of 69 , while from the age of 70 on men had a higher rate (figure 1).

\section{Diagnoses}

In the younger age group, more than half of the 771 who died with assistance had a cancer diagnosis and every fifth person was diagnosed with a disease of the nervous system, mainly multiple sclerosis (MS) or a motor neuron disease such as ALS (amyotrophic lateral sclerosis)(online supplementary table 3). Mental and behavioural disorders accounted for 45 assisted suicides $(5.8 \%)$, more than half of which were mood disorders. The percentage of assisted deaths among all deaths with the same potentially fatal underlying cause varied from $0.073 \%$ for diseases of the circulatory system to $5.25 \%$ for diseases of the nervous system (table 2). Looking at the diagnoses in more detail, the percentage of assisted deaths was highest among patients with MS (11.1\%) and Huntington's disease $(9.90 \%)$.

In the 65-94 age group, the percentage of assisted suicides with cancer was lower (39.3\%) (online supplementary table 3 ). Diseases of the nervous (11.8\%) and the circulatory system $(12.0 \%)$ each accounted for about one-eighth of assisted deaths. Among the 373 assisted deaths with diseases of the nervous system, patients with Parkinson's disease (106) and motor neuron diseases such as ALS (74) contributed most. Patients with musculoskeletal diseases comprised $10.0 \%$ of all assisted suicides, mainly arthropathies and dorsopathies, while $4.7 \%$ had diseases of the respiratory system. Mental and behavioural disorders accounted for $4.2 \%$ of all assisted suicides, the largest number of which were mood disorders, $2.9 \%$ followed by dementia at $0.8 \%$. The percentage of assisted deaths among all deaths (table 2) with the same underlying disease was highest for diseases of the nervous system (1.2\%).

\section{Multivariable Cox regression analysis}

The associations observed in the multivariable proportional hazard Cox models were very similar in the two time periods (figure 2 and online supplementary table $4)$, though some differed by age group. Men in the younger age group had a lower assisted suicide rate than women in both periods (HR of 0.78 in earlier and 0.77 in later period), but men in the older age group did not (respectively, HR 1.12 and 1.01). Having no religious affiliation and being Protestant were associated with higher rates of assisted suicide than being Catholic; the effect was stronger in the older age group. The association between a higher level of education and assisted suicide was stronger in the older age group, while in the younger age group persons with compulsory education had a $32 \%$ lower rate than those with secondary education in only the second period. Regarding marital status, the rate in 
Table 1 Characteristics, number and crude rates of assisted suicides

\begin{tabular}{|c|c|c|c|c|c|c|}
\hline \multirow[b]{2}{*}{ Characteristics } & \multicolumn{2}{|c|}{ Study population* } & \multicolumn{2}{|c|}{ Assisted suicides } & \multicolumn{2}{|c|}{$\begin{array}{l}\text { Crude rate (per } 100000 \text { person- } \\
\text { years) }\end{array}$} \\
\hline & Number & $\%$ & Number & $\%$ & Estimate & $95 \% \mathrm{Cl}$ \\
\hline \multicolumn{7}{|c|}{ (A) Study population 25-64 years old } \\
\hline All & 5102268 & 100 & 771 & 100 & 1.58 & 1.47 to 1.70 \\
\hline \multicolumn{7}{|l|}{ Gender } \\
\hline Male & 2568557 & 50.3 & 343 & 44.5 & 1.40 & 1.26 to 1.56 \\
\hline Female & 2533711 & 49.7 & 428 & 55.5 & 1.76 & 1.60 to 1.94 \\
\hline \multicolumn{7}{|l|}{ Calendar years } \\
\hline $2003 / 2004$ & 4045063 & 79.3 & 96 & 12.4 & 1.17 & 0.96 to 1.43 \\
\hline $2005 / 2006$ & $242768 \dagger$ & 4.8 & 101 & 13.1 & 1.23 & 1.01 to 1.50 \\
\hline $2007 / 2008$ & $246252 \dagger$ & 4.8 & 113 & 14.7 & 1.38 & 1.15 to 1.66 \\
\hline $2009 / 2010$ & $206220 \dagger$ & 4.0 & 134 & 17.4 & 1.65 & 1.39 to 1.95 \\
\hline $2011 / 2012$ & $188818 \dagger$ & 3.7 & 140 & 18.2 & 1.73 & 1.47 to 2.05 \\
\hline $2013 / 2014$ & $173147 \dagger$ & 3.4 & 187 & 24.2 & 2.34 & 2.03 to 2.70 \\
\hline \multicolumn{7}{|l|}{ Religious affiliation } \\
\hline Protestant & 1702781 & 33.4 & 275 & 35.7 & 1.74 & 1.54 to 1.96 \\
\hline Catholic & 2158382 & 42.3 & 205 & 26.6 & 0.99 & 0.87 to 1.14 \\
\hline No affiliation & 628032 & 12.3 & 245 & 31.8 & 3.91 & 3.45 to 4.23 \\
\hline Other/unknown & 613073 & 12.0 & 46 & 6.0 & 0.76 & 0.57 to 1.02 \\
\hline \multicolumn{7}{|l|}{ Education } \\
\hline Compulsory & 1137885 & 22.3 & 88 & 11.4 & 0.87 & 0.71 to 1.07 \\
\hline Secondary & 2420063 & 47.4 & 449 & 58.2 & 1.77 & 1.62 to 1.95 \\
\hline Tertiary & 977528 & 19.2 & 221 & 28.7 & 2.13 & 1.87 to 2.43 \\
\hline Unknown & 566792 & 11.1 & 13 & 1.7 & 0.43 & 0.25 to 0.75 \\
\hline \multicolumn{7}{|l|}{ Marital status } \\
\hline Single & 1715805 & 33.6 & 176 & 22.8 & 1.25 & 1.08 to 1.45 \\
\hline Married & 2831208 & 55.5 & 383 & 49.7 & 1.31 & 1.19 to 1.45 \\
\hline Widowed & 99092 & 1.9 & 29 & 3.76 & 3.83 & 2.66 to 5.51 \\
\hline Divorced & 456163 & 9.0 & 183 & 23.74 & 3.85 & 3.33 to 4.45 \\
\hline \multicolumn{7}{|l|}{ Type of household } \\
\hline 1 person & 772331 & 15.1 & 255 & 33.1 & 3.20 & 2.83 to 3.62 \\
\hline$\geq 2$ persons & 4183879 & 82.0 & 498 & 64.6 & 1.26 & 1.16 to 1.38 \\
\hline Institutions & 146058 & 2.9 & 18 & 2.3 & 1.25 & 0.79 to 1.99 \\
\hline \multicolumn{7}{|l|}{ Children } \\
\hline No & 2226028 & 43.6 & 318 & 41.2 & 1.57 & 1.41 to 1.75 \\
\hline Yes & 2566001 & 50.3 & 414 & 53.7 & 1.61 & 1.46 to 1.77 \\
\hline Unknown & 310239 & 6.1 & 39 & 5.1 & 1.42 & 1.03 to 1.94 \\
\hline \multicolumn{7}{|l|}{ Urbanicity } \\
\hline Urban & 1445955 & 28.3 & 265 & 34.4 & 1.88 & 1.66 to 2.12 \\
\hline Periurban & 2321284 & 45.5 & 370 & 48.0 & 1.68 & 1.51 to 1.86 \\
\hline Rural & 1335029 & 26.2 & 136 & 17.6 & 1.08 & 0.91 to 1.28 \\
\hline \multicolumn{7}{|c|}{ Neighbourhood index of SEP } \\
\hline Lowest quartile & 1242745 & 24.4 & 111 & 14.4 & 0.94 & 0.78 to 1.13 \\
\hline Second quartile & 1220105 & 23.9 & 156 & 20.2 & 1.34 & 1.14 to 1.56 \\
\hline Third quartile & 1225580 & 24.0 & 196 & 25.4 & 1.67 & 1.45 to 1.92 \\
\hline
\end{tabular}


Table 1 Continued

\begin{tabular}{|c|c|c|c|c|c|c|}
\hline Characteristics & \multicolumn{2}{|c|}{ Study population* } & \multicolumn{2}{|c|}{ Assisted suicides } & \multicolumn{2}{|c|}{$\begin{array}{l}\text { Crude rate (per } 100000 \text { perso } \\
\text { years) }\end{array}$} \\
\hline Fourth quartile & 1222208 & 23.9 & 284 & 36.8 & 2.45 & 2.18 to 2.75 \\
\hline \multicolumn{7}{|l|}{ Language region } \\
\hline German & 3666753 & 71.87 & 548 & 71.1 & 1.56 & 1.44 to 1.70 \\
\hline Italian & 219002 & 4.29 & 14 & 1.8 & 0.67 & 0.40 to 1.13 \\
\hline Rhaeto-Roman & 17055 & 0.33 & - & & & \\
\hline \multicolumn{7}{|l|}{ Nationality } \\
\hline Swiss & 3928264 & 77.0 & 699 & 90.7 & 1.89 & 1.75 to 2.03 \\
\hline \multicolumn{7}{|l|}{ Gender } \\
\hline Male & 959044 & 44.8 & 1336 & 42.2 & 19.97 & 18.93 to 21.07 \\
\hline Female & 1180108 & 55.2 & 1834 & 57.9 & 20.72 & 19.79 to 21.69 \\
\hline \multicolumn{7}{|l|}{ Calendar years } \\
\hline $2003 / 2004$ & 1227529 & 57.4 & 282 & 8.9 & 12.24 & 10.89 to 13.76 \\
\hline $2005 / 2006$ & $161701 \dagger$ & 7.6 & 326 & 10.3 & 13.67 & 12.2 to 15.24 \\
\hline $2007 / 2008$ & $184728 \dagger$ & 8.6 & 357 & 11.3 & 14.30 & 12.89 to 15.86 \\
\hline $2009 / 2010$ & $187522 \dagger$ & 8.8 & 474 & 15.0 & 18.00 & 16.45 to 19.70 \\
\hline $2011 / 2012$ & $191358 \dagger$ & 8.9 & 692 & 21.8 & 24.85 & 23.06 to 26.77 \\
\hline Other/unknown & 141153 & 6.6 & 196 & 6.2 & 20.82 & 18.11 to 23.95 \\
\hline \multicolumn{7}{|l|}{ Education } \\
\hline Compulsory & 689219 & 32.2 & 600 & 18.9 & 11.61 & 10.72 to 12.58 \\
\hline Secondary & 1043833 & 48.8 & 1688 & 53.3 & 22.41 & 21.36 to 23.50 \\
\hline Tertiary & 377305 & 17.6 & 850 & 26.8 & 32.15 & 30.06 to 34.38 \\
\hline Unknown & 28795 & 1.4 & 32 & 1.0 & 16.24 & 11.49 to 22.97 \\
\hline \multicolumn{7}{|l|}{ Marital status } \\
\hline Single & 171876 & 8.0 & 259 & 8.2 & 22.03 & 19.50 to 24.88 \\
\hline Married & 1274969 & 59.6 & 1301 & 41.0 & 14.20 & 13.45 to 14.99 \\
\hline Widowed & 480234 & 22.5 & 1105 & 34.9 & 28.98 & 27.32 to 30.74 \\
\hline Divorced & 212073 & 9.9 & 505 & 15.9 & 36.26 & 33.24 to 39.57 \\
\hline \multicolumn{7}{|l|}{ Type of household } \\
\hline 1 person & 518958 & 24.3 & 1211 & 38.2 & 31.29 & 29.58 to 33.11 \\
\hline$\geq 2$ persons & 1546029 & 72.3 & 1878 & 59.2 & 16.62 & 15.88 to 17.39 \\
\hline Institutions & 74165 & 3.4 & 81 & 2.6 & 21.86 & 17.58 to 27.17 \\
\hline \multicolumn{7}{|l|}{ Children } \\
\hline No & 339093 & 15.9 & 713 & 22.5 & 30.75 & 28.57 to 33.09 \\
\hline
\end{tabular}

Continued 
Table 1 Continued

\begin{tabular}{|c|c|c|c|c|c|c|}
\hline \multirow[b]{2}{*}{ Characteristics } & \multicolumn{2}{|c|}{ Study population* } & \multicolumn{2}{|c|}{ Assisted suicides } & \multicolumn{2}{|c|}{$\begin{array}{l}\text { Crude rate (per } 100000 \text { person- } \\
\text { years) }\end{array}$} \\
\hline & Number & $\%$ & Number & $\%$ & Estimate & $95 \% \mathrm{Cl}$ \\
\hline Yes & 1698737 & 79.4 & 2316 & 73.1 & 18.49 & 17.75 to 19.26 \\
\hline Unknown & 101322 & 4.7 & 141 & 4.4 & 20.16 & 17.10 to 23.78 \\
\hline \multicolumn{7}{|l|}{ Urbanicity } \\
\hline Urban & 640844 & 29.9 & 1306 & 41.2 & 27.79 & 26.33 to 29.34 \\
\hline Periurban & 955312 & 44.7 & 1472 & 46.4 & 21.25 & 20.20 to 22.37 \\
\hline Rural & 542996 & 25.4 & 392 & 12.4 & 10.00 & 9.06 to 11.05 \\
\hline \multicolumn{7}{|c|}{ Neighbourhood index of SEP } \\
\hline Lowest quartile & 475150 & 22.2 & 383 & 12.1 & 11.11 & 10.05 to 12.28 \\
\hline Second quartile & 509464 & 23.8 & 537 & 16.9 & 14.42 & 13.25 to 15.69 \\
\hline Third quartile & 517807 & 24.2 & 778 & 24.5 & 20.54 & 19.15 to 22.04 \\
\hline Fourth quartile & 557424 & 26.1 & 1384 & 43.7 & 33.74 & 32.01 to 35.57 \\
\hline Unknown & 79307 & 3.7 & 88 & 2.8 & 18.23 & 14.80 to 22.47 \\
\hline \multicolumn{7}{|l|}{ Language region } \\
\hline German & 1524965 & 71.3 & 2288 & 72.2 & 20.68 & 19.85 to 21.54 \\
\hline French & 497621 & 23.3 & 814 & 25.7 & 22.57 & 21.07 to 24.17 \\
\hline Italian & 108006 & 5.0 & 64 & 2.0 & 7.92 & 6.20 to 10.12 \\
\hline Rhaeto-Roman & 8560 & 0.4 & 4 & 0.1 & 6.37 & 2.39 to 16.96 \\
\hline \multicolumn{7}{|l|}{ Nationality } \\
\hline Swiss & 1881034 & 87.9 & 2961 & 93.4 & 21.57 & 20.80 to 22.36 \\
\hline Foreigner & 258118 & 12.1 & 209 & 6.6 & 11.53 & 10.07 to 13.21 \\
\hline
\end{tabular}

${ }^{*}$ At entry in study.

†People who entered the study at their 25th birthday.

SEP, socioeconomic position.

the younger age group of those who were divorced was $70 \%$ higher in the second period compared with married people. In the older age group, widowed persons had a 33\%-40\% higher assisted suicide rate, and the rate among the divorced was around two times as high as that of those who were married. Living in a neighbourhood with a higher socioeconomic index was associated with a higher hazard of assisted suicide. People living in the French-speaking region had a higher rate than people living in the German-speaking region, although the effect was not statistically significant in younger people in the first period. In the second, younger (HR 0.35) and older people (HR 0.48) living in the Italian-speaking region had a lower rate than people living in the German-speaking region. Compared with Swiss citizens, foreigners living in Switzerland were less likely to die with a right-to-die organisation.

\section{Multivariable logistic regression analysis}

We further analysed the odds of assisted suicides among all deaths with a multivariable logistic regression model (online supplementary table 5). The associations were mostly the same as in the Cox proportional hazard model, with one main exception: in the logistic regression models, men had lower odds than women in the younger group (OR 0.52 in the earlier and 0.54 in the later period), and in the older age group (respectively, OR 0.64 and 0.65 ). To analyse differences between age groups 25-64 and 65-94 years over time, we fitted multivariable logistic regression models in the entire data set with interaction terms. The model showed a significant interaction between age group and period $\left(\chi^{2}=10.4, \mathrm{df}=1\right.$, $\mathrm{p}=0.0013)$ with a larger increase in the older group than the younger group over time (OR of 2.25 compared with 1.72).

Compared with patients who died with cancer during study period, decedents with a disease of the nervous system on the death certificate were more likely to have died with assistance (respectively, OR of 6.91 and 6.76 in the younger age group, 1.53 and 1.47 in the older age group). In the older age group, the odds for diseases of the circulatory system, diseases of the respiratory system and other diseases were substantially lower. As diseases of the musculoskeletal system are in themselves rarely fatal, the odds for assisted dying were high in all analyses. The associations between diagnoses and time periods were statistically significant in the likelihood ratio test for interactions $(\mathrm{p}=0.0018$ in the younger age group and $\mathrm{p}<0.001$ in the older age group) (online supplementary 


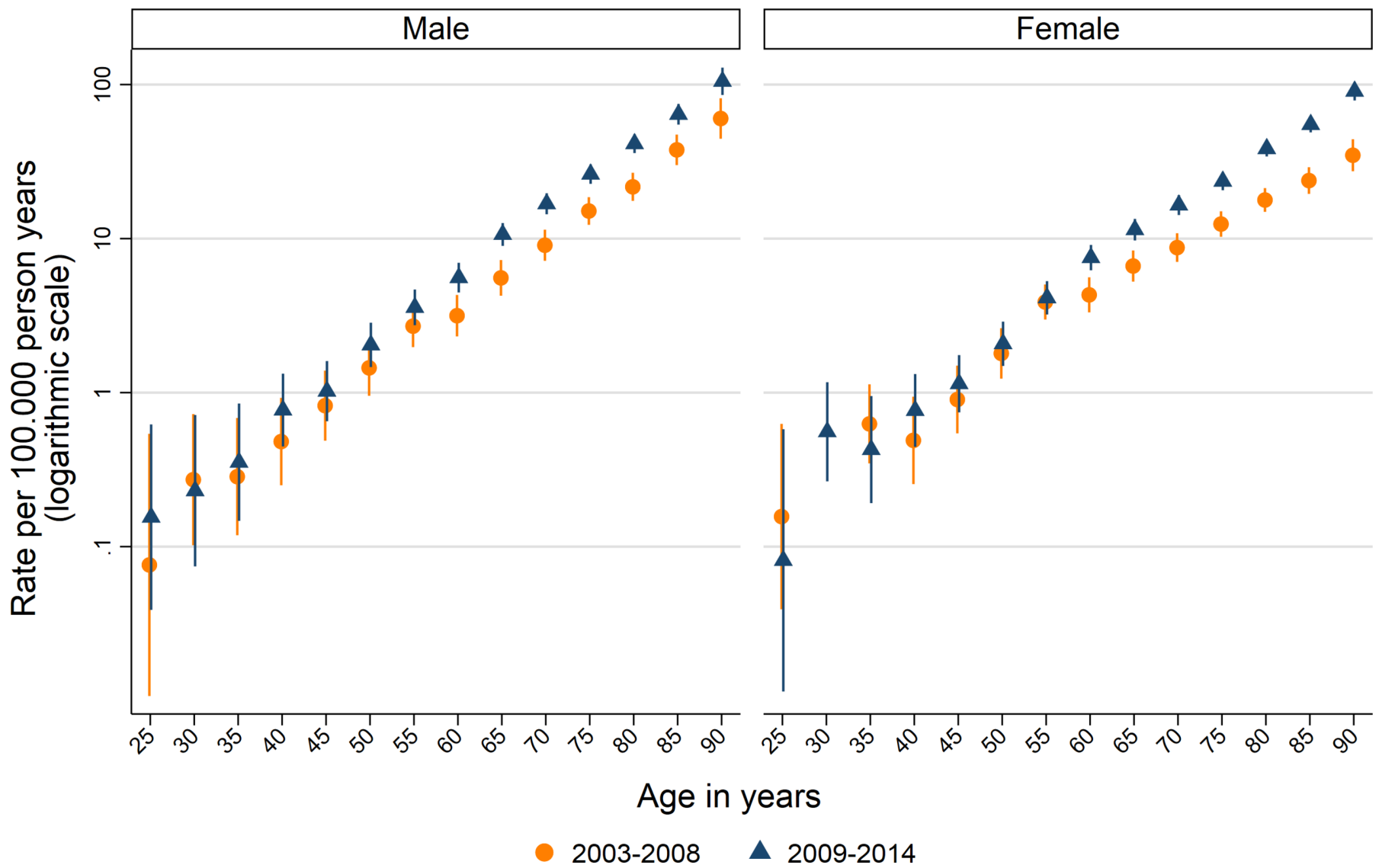

Figure 1 Crude rate of assisted suicide by age and time period (2003-2008 and 2009-2014) for men and women.

table 6). In both age groups, the odds of having no diagnoses on death certificates clearly decreased from the first to the second period (online supplementary table 7). In the older age group, the odds of dying with diseases of the respiratory or the musculoskeletal system increased (online supplementary table 7).

\section{DISCUSSION}

Crude rates of assisted suicide in Switzerland more than tripled from 2003 to 2014, and assisted suicides accounted for $1.3 \%$ of all deaths in 2014. The increase was greater in the 65-94 age group than in those younger than 65 but is independent of socioeconomic factors such as gender, and characteristics of the individual and the household. Factors associated with assisted suicide from 2003 to 2008 were the same as those associated with assisted suicide from 2009 to 2014: female gender, higher education, having no religious affiliation, no children and a Swiss passport, living in a neighbourhood with a higher areabased socioeconomic index, and in the French-speaking part of Switzerland were associated with a higher rate of assisted suicides. In the younger age group, people living alone were more likely to die with assistance, as were in the older age group the widowed and the divorced. Cancer, diseases of the nervous system and-in the older age group-of the circulatory and the respiratory system were the most common diagnoses on death certificates of people who died with assistance. Diagnoses shifted between time periods; with less death certificates with no first underlying diseases in the second period, and in the older age group, diseases of the respiratory and the musculoskeletal system increased. Percentages of assisted suicides among all deaths were highest in diseases of the nervous system.

The strong increase in incidence of assisted suicide in Switzerland is based on a broad acceptance in the Swiss population that has been confirmed by referenda and surveys. ${ }^{30-32}$ The increase is also in line with the development in other European countries with long-term experience in assisted dying. ${ }^{13-17}$ In Belgium, the number of reported cases increased more than sevenfold since 2003. In 2013, more than 1800 people died by euthanasia, corresponding to $1.7 \%$ of all deaths. ${ }^{14}$ As in our study, the increase occurred in both sexes and all age groups, and the proportion grew among older patients. In the Netherlands, the number of reported assisted deaths, largely euthanasia, reached 5500 in $2015,{ }^{15}$ three times higher than in 2003, which corresponds to almost $4 \%$ of all deaths. In US states with long-term experience with assisted dying, the number of assisted suicides also increased, ${ }^{161719}$ but with roughly 130 in Oregon (2016) and 200 in Washington ${ }^{17}$ the numbers are significantly lower than in Europe.

The stability of socioeconomic factors associated with assisted suicide over the study period does not support the slippery slope hypothesis: assisted suicides did not 
Table 2 Percentage of assisted suicides among all deaths with the same, potentially fatal, underlying disease, by age group and period for broad (bold) and detailed categories of diagnoses

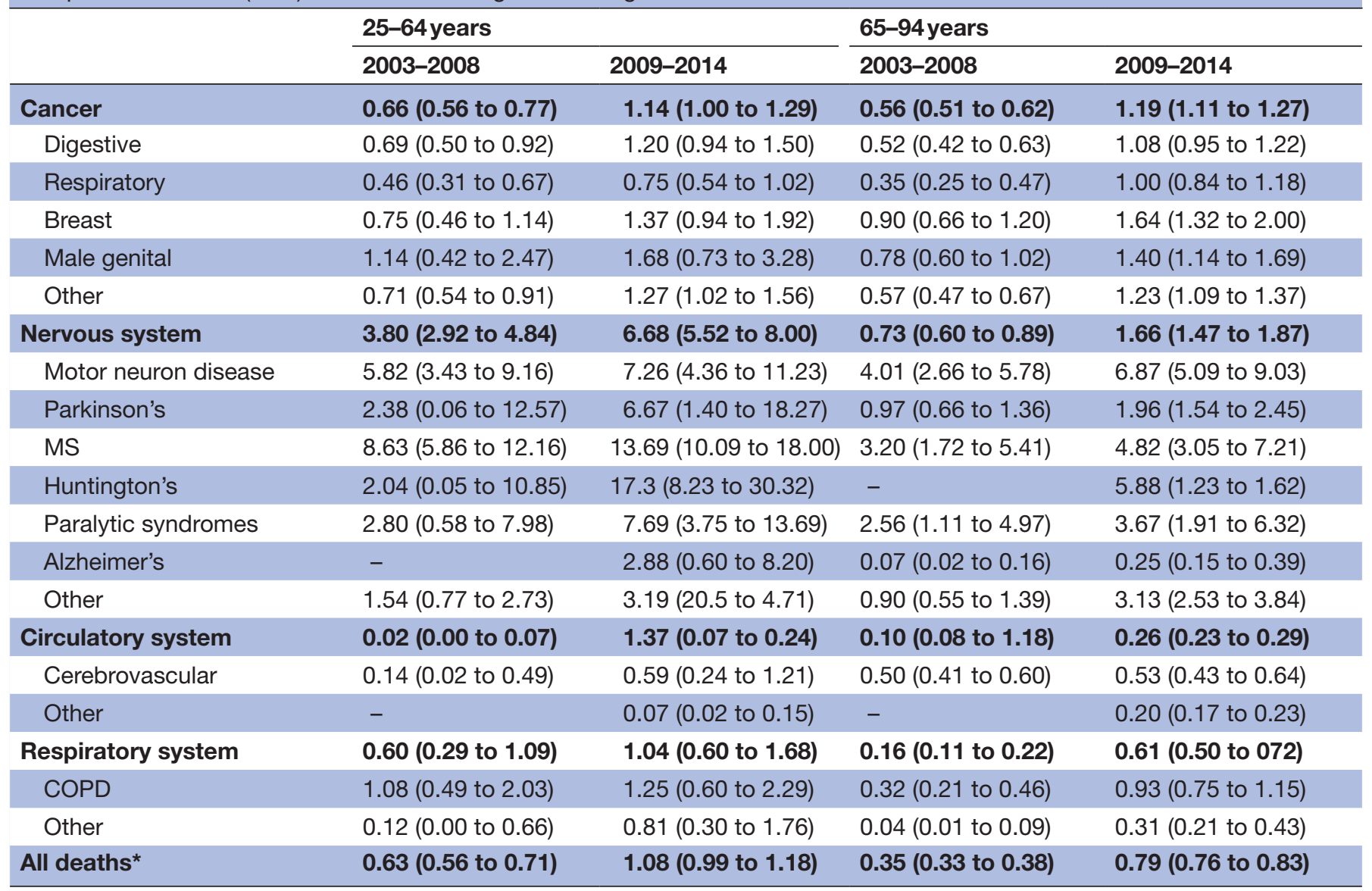

MS, multiple sclerosis. COPD, chronic obstructive pulmonary disease

* from potentially fatal diseases

increase disproportionally among less educated people and people living in neighbourhoods with lower socioeconomic status. Other factors persistently associated with assisted suicide-female gender, having no children and living alone, being widowed or divorced-may reflect a degree of social vulnerability. Of note, persons who were single and had no children were less likely to get their request for euthanasia granted in a Dutch end-oflife clinic. ${ }^{33}$

\section{Strengths and limitations}

This is the first study we know of that looked at trends in the association of assisted dying with detailed socioeconomic characteristics over a period greater than 10 years. It is based on individual, household and building-level data from the census 2000 with virtually complete coverage, and selection or response biases are therefore unlikely. However, census 2000 information is not completely up to date in 2014 for all persons. Type of household, in particular, may have changed over the 14 years of follow-up, and also urbanicity, the socioeconomic neighbourhood index, language region, the existence of children, and self-declared religion and nationality; changes over time are more likely in the younger than in the older age group. We were able to account for the fact that marital status might change, and more accurately analyse the association of widowhood or divorce with assisted suicide. We did not have any direct, individual data for economic well-being. However, education is an important dimension of socioeconomic status itself, and it precedes and influences other personal attributes such as occupation and personal income. ${ }^{34}$ Added to that information, we also had socioeconomic status at the neighbourhood level for each person. ${ }^{29}$

An increasing number of countries and states in the $\mathrm{USA}^{2}$ have legalised assisted suicide in recent years or are in the process of doing so. Switzerland is one of the few countries with long-term experience that allows studying time trends and the possible change of predictors. The FSO makes a great effort to identify assisted suicides in the mortality statistics in cooperation with right-to-die organisations, cantonal institutes of forensic medicine and physicians. In suspected cases, the FSO consults the responsible physician. The risk of classifying deaths wrongly as assisted is therefore small. However, because there is no obligation to report assisted suicides to a central registry, identification of assisted deaths 
25-64 years old

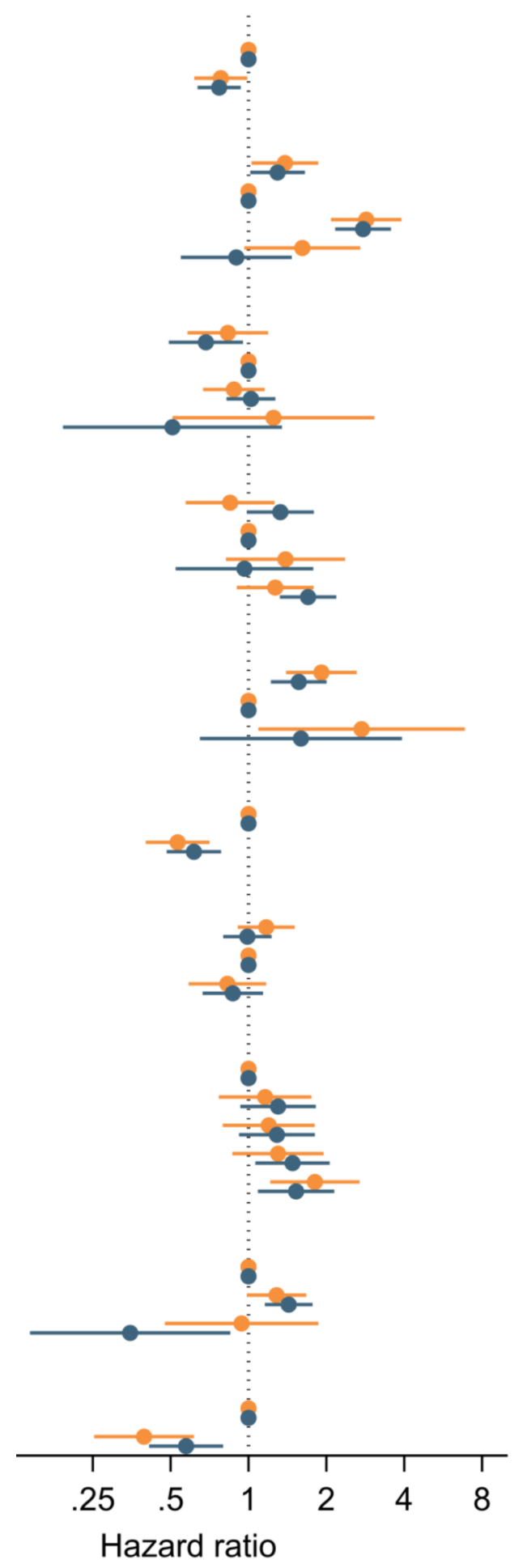

65-94 years old

\section{Gender \\ Female \\ Male}

Religion

Protestant Church

Roman Catholic Church

No religious affiliation

Other/unknown

Education

Compulsory education or less

Upper secondary level education

Tertiary level education

Not known

\section{Marital status}

Single

Married

Widowed

Divorced

Type of household

Single person household

Two or more persons

Home, institution

$$
\begin{gathered}
\text { Children } \\
\text { No } \\
\text { Yes }
\end{gathered}
$$

Urbanicity

Urban

Peri-urban

Rural

Quintiles SSEP

Lowest quintile

Second quintile

Third quintile

Fourth quintile

Highest quintile

\section{Language region \\ German \\ French \\ Italian}
Nationality
Swiss

Non-Swiss

\section{Time period}

is likely not complete. Suicides assisted without the involvement of one of the three main organisations may in particular be missed. In recent years, smaller rightto-die organisations have become active: LifeCircle in the region of Basel and LLExit in the Italian-speaking part of Switzerland. It is possible that differences in process and reporting may increase the proportion of assisted suicides that are not identified by the FSO, and therefore at least partly explain the lower increase of assisted suicides in the Italian-speaking region of Switzerland. A Belgian study showed that differences in end-of-life practices found between the language regions of Flanders 
and Wallonia were caused by differences in acceptance, and by differences in the process and reporting compliance. ${ }^{35}$ It is also possible that physicians not associated with right-to-die organisations do assist in suicides and do not report these cases appropriately. Even though this is considered a marginal problem compared with the numbers of suicides assisted by right-to-die organisations in Switzerland, there are no numbers because of the lack of an obligatory register. In a survey in 2006, 103 out of 1650 doctors had assisted a suicide without involvement of a right-to-die association. ${ }^{36}$

Another limitation of our study is the fact that death certificates were the only source for information about the underlying disease. They did not provide nor did we have other sources of information on stage of disease, treatments and their alternatives, and when patients decided to die with assistance. The comparability of the figures for assisted deaths among all deaths for different diseases is also limited. For assisted deaths involving non-fatal or rarely fatal mental disorders or diseases of the musculoskeletal system, the denominator does not fully reflect the number of persons, thus, afflicted and percentages of these assisted deaths are therefore not comparable to those involving fatal diseases. Finally, we have the matter of the reliability of death certificates. While their reliability for major disease groups such as cancer and well-defined rare conditions such as ALS is high, ${ }^{37} 38$ reliability is low for chronic conditions such as diabetes and renal insufficiency. ${ }^{37}$ In Switzerland, assisted suicides are treated as unnatural deaths and are investigated by a forensic team, which relies on documents of the right-to-die organisations. ${ }^{39}$ This might lead to a more accurate diagnoses on death certificates of persons dying with assistance compared with those who have natural deaths.

The shift in diagnoses observed in our study may be at least partially explained by the change in the coding system of the FSO. The fact that assisted suicide was not a primary cause of death from 2009 onwards may have increased the coding of the underlying diseases. However, further studies are needed to monitor the development of diagnoses associated with assisted suicide. These studies ideally should be based on death certificates and recover information on severity and stage of patients' diseases and the treatments they underwent.

In summary, our study results show that the increase in assisted suicides in Switzerland was more pronounced in the older of the two age groups, but not associated with changing association with socioeconomic and other factors. However, in a context of assisted suicide, vulnerability may not be limited to factors such as socioeconomic status, living alone, being widowed or divorced. Serious illness, possibly accompanied by heavy pain with no prospect of improvement, and also mere old age may make any person more vulnerable. Register based, sensitive monitoring of the characteristics of assisted deaths and their underlying diagnoses should be implemented to identify trends and possible omissions in the health management of specific groups.
Acknowledgements The authors thank the Swiss Federal Statistical Office for providing mortality and census data and for the support which made the Swiss National Cohort and this study possible. The authors would like to thank Christopher Ritter for editorial services.

Collaborators The members of the Swiss National Cohort Study Group are Matthias Egger, Adrian Spoerri and Marcel Zwahlen (all Bern), Milo Puhan and Matthias Bopp (both Zurich), Martin Röösli (Basel), Murielle Bochud (Lausanne) and Michel Oris (Geneva).

Contributors NS, CJ and MZ developed the study design. CJ did the identification of the assisted suicides and the data preparation. NS did the data processing and analyses, and wrote the first draft of the paper. MZ supervised the statistical analyses. All authors critically revised the first draft and approved the final manuscript submitted for publication.

Funding This work was supported by the Swiss National Science Foundation (grant numbers: 325130_160171 and 33CS30_148415).

Competing interests None declared.

Patient consent Not required.

Ethics approval Approval for the Swiss National Cohort study was obtained from the ethics committees of the cantons of Zurich and Bern. A data centre was established at ISPM Bern, but for analyses conducted there of this type of study formal consent is not required.

Provenance and peer review Not commissioned; externally peer reviewed.

Data sharing statement Individual data from different data sets were used for the construction of the SNC. All these data are the property of the Swiss FSO and can only be made available by legal agreements with the Swiss FSO. This also applies to derivatives such as the analysis files used for this study. However, after approval of the SNC Scientific Board, a specific SNC module contract with Swiss FSO allows researchers to receive analysis files for replication of the analysis. Data requests should be sent to Professor Milo Puhan (chairman of the SNC Scientific Board, miloalan.puhan@uzh.ch).

Open Access This is an Open Access article distributed in accordance with the Creative Commons Attribution Non Commercial (CC BY-NC 4.0) license, which permits others to distribute, remix, adapt, build upon this work non-commercially, and license their derivative works on different terms, provided the original work is properly cited and the use is non-commercial. See: http://creativecommons.org/ licenses/by-nc/4.0/

(c) Article author(s) (or their employer(s) unless otherwise stated in the text of the article) 2018. All rights reserved. No commercial use is permitted unless otherwise expressly granted.

\section{REFERENCES}

1. Steck N, Egger M, Maessen M, et al. Euthanasia and assisted suicide in selected European countries and US states: systematic literature review. Med Care 2013;51:938-44.

2. Emanuel EJ, Onwuteaka-Philipsen BD, Urwin JW, et al. Attitudes and Practices of Euthanasia and Physician-Assisted Suicide in the United States, Canada, and Europe. JAMA 2016;316:79-90.

3. Burkhardt S, La Harpe R. Debates about assisted suicide in Switzerland. Am J Forensic Med Pathol 2012;33:410-3.

4. The Federal Council. Schweizerisches Strafgesetzbuch. Switzerland: The Federal Council, 1937.

5. Swiss Tribunal Federal. Judgements $2 A .48 / 2006$ and 2A.66/2006. Switzerland: Swiss Tribunal Federal, 2006.

6. Bosshard G, Fischer S, Bär W. Open regulation and practice in assisted dying. Swiss Med Wkly 2002;132:527-34.

7. Steck N, Junker C, Maessen M, et al. Swiss National Cohort. Suicide assisted by right-to-die associations: a population based cohort study. Int J Epidemiol 2014;43:614-22.

8. Bosshard G, Zellweger U, Bopp M, et al. Medical End-of-Life Practices in Switzerland: A Comparison of 2001 and 2013. JAMA Intern Med 2016;176:555-6.

9. FSO. Assistierter Suizid (Sterbehilfe) und Suizid in der Schweiz. BFS Aktuell. Switzerland: Federal Statistical Office, 2016:1-4.

10. Exit. Annual reports. Secondary Annual reports. https://www.exit.ch/ news/jahresberichte/jahresbericht-2016/ (accessed 23 Jan 2018).

11. Dignitas. Annual reports. Secondary Annual reports. http://www. dignitas.ch/index.php?option=com_content\&view=article\&id=24\& Itemid=64\&lang=de (accessed 23 Jan 2018). 
12. Exit ADMD. Annual reports. Secondary Annual reports. 2018 http:// www.exit-geneve.ch/journalistes.html (accessed 23 Jan 2018).

13. Dyer O, White C, García Rada A. Assisted dying: law and practice around the world. BMJ 2015;351:h4481.

14. Dierickx S, Deliens L, Cohen J, et al. Euthanasia in Belgium: trends in reported cases between 2003 and 2013. CMAJ 2016;188:E407-14.

15. Regional euthanasia review c. JAARVERSLAG 2016;2015.

16. Oregon Health Authority. Oregon Death with Dignity Act: Data summary 2016. Oregon: Oregon Health Authority, 2017:12.

17. Washington State Departement of Health. Death with Dignity Act Report 2015. Washington: Washington State Departement of Health, 2016.

18. Chambaere K, Bilsen J, Cohen J, et al. Trends in medical end-of-life decision making in Flanders, Belgium 1998-2001-2007. Med Decis Making 2011;31:500-10.

19. Hedberg K, New C. Oregon's Death With Dignity Act: 20 Years of Experience to Inform the Debate. Ann Intern Med 2017;167:579-83.

20. van der Heide A, van Delden JJM, Onwuteaka-Philipsen BD. Endof-Life Decisions in the Netherlands over 25 Years. N Engl J Med 2017;377:492-4

21. Lerner BH, Caplan AL. Euthanasia in Belgium and the Netherlands: On a Slippery Slope? JAMA Intern Med 2015;175:1640-1.

22. Lewis $P$. The empirical slippery slope from voluntary to non-voluntary euthanasia. J Law Med Ethics 2007;35:197-210.

23. Calabrò RS, Naro A, De Luca R, et al. The Right to Die in Chronic Disorders of Consciousness: Can We Avoid the Slippery Slope Argument? Innov Clin Neurosci 2016;13(11-12):12-24

24. Bopp M, Spoerri A, Zwahlen M, et al. Cohort Profile: the Swiss National Cohort--a longitudinal study of 6.8 million people. Int $J$ Epidemiol 2009;38:379-84.

25. Spoerri A, Zwahlen M, Egger M, et al. The Swiss National Cohort: a unique database for national and international researchers. Int $J$ Public Health 2010;55:239-42.

26. Renaud A. Methodology Report - Coverage Estimation for the Swiss Population Census 2000. Swiss: Federal Statistical Office, 2004.

27. Andorno R. Nonphysician-assisted suicide in Switzerland. Camb Q Healthc Ethics 2013;22:246-53.

28. WHO. International Statistical Classification of Diseases and Related Health Problems: Instruction manual. Geneva: WHO, 2010:1-201.
29. Panczak R, Galobardes B, Voorpostel M, et al. Swiss National Cohort and Swiss Household Panel. A Swiss neighbourhood index of socioeconomic position: development and association with mortality. J Epidemiol Community Health 2012;66:1129-36.

30. Zürich K. Kantonale Volksinitiative zur Einreichung einer Standesinitiative "Stopp der Suizidhilfe!". Secondary Kantonale Volksinitiative zur Einreichung einer Standesinitiative "Stopp der Suizidhilfe!". 2011 http://www.wahlen-abstimmungen.zh.ch/ internet/justiz_inneres/wahlen-abstimmungen/de/abstimmungen/ abstimmungsarchiv.html (accessed 22 Mar 2017)

31. Zürich K. Kantonale Volksinitiative "Nein zum Sterbetourismus im Kanton Zürich!" Secondary Kantonale Volksinitiative "Nein zum Sterbetourismus im Kanton Zürich!" 2011. http://www.wahlenabstimmungen.zh.ch/internet/justiz_inneres/wahlen-abstimmungen/ de/abstimmungen/abstimmungsarchiv.html (accessed $22 \mathrm{Mar}$ 2017)

32. Vaud K. Assistance au suicide. Secondary Assistance au suicide 2012. 2012 http://www.elections.vd.ch/votelec/results.html?scrutin= VDVO20120617 (accessed 22 Mar 2017)

33. Snijdewind MC, Willems DL, Deliens L, et al. A Study of the First Year of the End-of-Life Clinic for Physician-Assisted Dying in the Netherlands. JAMA Intern Med 2015;175:1633-40.

34. Mirowsky JRC. Education, Social Status, and Health. Hawthorne, NY: Aldine de Gruyter, 2003

35. Cohen J, Van Wesemael Y, Smets T, et al. Cultural differences affecting euthanasia practice in Belgium: one law but different attitudes and practices in Flanders and Wallonia. Soc Sci Med 2012;75:845-53.

36. Burkhardt S, Wyss K, La Harpe R. [Assisted suicide in Switzerland: physicians' position]. Rev Med Suisse 2007;3:2861-4.

37. Harteloh $\mathrm{P}$, de Bruin K, Kardaun J. The reliability of cause-of-death coding in The Netherlands. Eur J Epidemiol 2010;25:531-8.

38. Chiò A, Magnani C, Oddenino E, et al. Accuracy of death certificate diagnosis of amyotrophic lateral sclerosis. J Epidemiol Community Health 1992;46:517-8.

39. Bartsch C. Praxis und Probleme des assistierten Suizids in der Schweiz aus rechtsmedizinischer Sicht. In: Welsch CO, Frewer A, Bielefeld $\mathrm{H}$, eds. Autonomie und Menschenrechte am Lebensende. Boston: Transcript Verlag, 2016:203-20. 